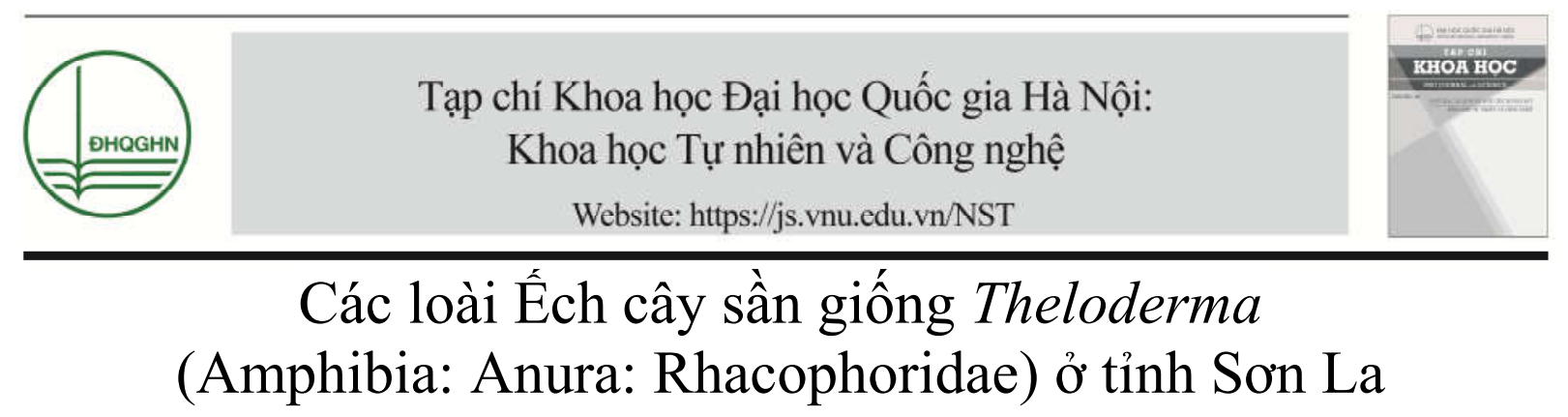

\author{
Phạm Văn Anh ${ }^{1, *}$, Nguyễn Quảng Trường ${ }^{2,3}$ \\ ${ }^{1}$ Truòng Đại học Tây Bắc, thành phố Sơn La, Sơn La, Việt Nam \\ ${ }^{2}$ Viện Sinh thái và Tài nguyên Sinh vật, Viện Hàn lâm Khoa học và Công nghệ Việt Nam, \\ 18 Hoàng Quốc Việt, Hà Nội, Việt Nam \\ Nhận ngày 16 tháng 8 năm 2017 \\ Chỉnh sửa ngày 20 tháng 9 năm 2017; Chấp nhận đăng ngày 10 tháng 10 năm 2017
}

\begin{abstract}
Tóm tắt: Nghiên cứu từ năm 2012 đến 2016 tại tỉnh Sơn La, chúng tôi đã ghi nhận được 5 loài ếch cây sần thuộc giống Theloderma. Trong đó có tới 4 loài lần đầu tiên ghi nhận ở tỉnh này: Theloderma albopunctatum, $T$. bicolor, $T$. gordoni và $T$. lateriticum. Những ghi nhận mới này đã nâng tổng số loài ếch nhái ghi nhận được cho tới nay ở tỉnh Sơn La lên 45 loài. Bên cạnh đó, chúng tôi cũng cung cấp những thông tin bổ sung về đặc điểm nơi sống của các loài ếch cây sần nói trên.
\end{abstract}

Tù khóa: Copia, Ghi nhận mới, Mường Do, Mường La, Sốp Cộp, Theloderma

\section{Mở đầu}

Sơn La là tỉnh miền núi Tây Bắc Việt Nam, với diện tích $14.125 \mathrm{~km}^{2}$, độ che phủ rừng khoảng $40 \%$, trong đó rừng tự nhiên còn khoảng 439.592 ha (Cục Kiểm lâm, 2014) [1]. Tuy nhiên, kết quả nghiên cứu về đa dạng sinh học nói chung và lưỡng cư nói riêng ở tỉnh Sơn La còn rất hạn chế, trong đó có một số công trình nghiên cứu về lưỡng cư như: Lê Nguyên Ngật và nnk (2009) ghi nhận 22 loài ở KBTTN Copia [2]; Nguyen et al. (2009) ghi nhận 33 loài ở toàn tỉnh Sơn La [3]; Nguyễn Văn Sáng và nnk (2010) ghi nhận 28 loài ở KBTTN Xuân Nha [4]. Gần đây Phạm Văn Anh và nnk (2015)

\footnotetext{
*Tác giả liên hệ. ĐT.: 84-984858128.

Email: phamanhdhsphn@gmail.com

https://doi.org/10.25073/2588-1140/vnunst.4714
}

đã ghi nhận 12 loài lưỡng cư ở thành phố Sơn La [5]. Kết quả của các nghiên cứu trên đã ghi nhận tổng số 41 loài lưỡng cư ở tỉnh Sơn $\mathrm{La}$, tuy nhiên chỉ ghi nhận một loài loài thuộc giống Theloderma là Ểch cây sần bắc bộ Theloderma corticale [3].

Trong các chuyến khảo sát về đa dạng sinh học từ năm 2012 đến năm 2016 tại hai KBTTN Copia và Sốp Cộp, xã Mường Do (huyện Phù Yên) và xã Ngọc Chiến (huyện Mường La), chúng tôi đã thu thập được mẫu vật của các loài thuộc giống Theloderma, trong đó có 4 loài lần đầu tiên được ghi nhận cho tỉnh Sơn La. Bài báo này cung cấp dẫn liệu cập nhật về đa dạng thành phần loài ếch cây sần ở tỉnh Sơn La đồng thời mô tả đặc điểm hình thái, sinh thái của 4 loài mới ghi nhận bổ sung. 


\section{Nguyên liệu và phương pháp}

Khảo sát thực địa được tiến hành từ tháng 1 đến tháng 11 trong các năm 2012 đến 2016 ở hai KBTTN Copia và Sốp Cộp với tổng số 138 ngày; 3 đợt vào tháng 4/2015, 4 và 5/2016 ở xã Ngọc Chiến, huyện Mường La; 18 ngày và 4 đợt ở xã Mường Do, huyện Phù Yên (4-5/2015; $8-9 / 2015 ; 11 / 2015$ và $6 / 2016), 19$ ngày (Hình 1$)$.

Thời gian thu thập mẫu vật từ 9:00 đến 24:00. Mẫu vật ếch nhái chủ yếu thu thập bằng tay và đựng trong các túi nilon hoặc túi vải cõ̃ nhỏ. Mẫu vật sau khi chụp ảnh được gây mê bằng ethylacetate, đeo nhãn và định hình trong cồn $80 \%$ trong vòng 4-5 tiếng, sau đó chuyển sang ngâm bảo quản trong cồn $70 \%$. Mẫu vật hiện đang được lưu giữ tại phòng mẫu khoa Sinh - Hóa, trường Đại học Tây Bắc (TBU).

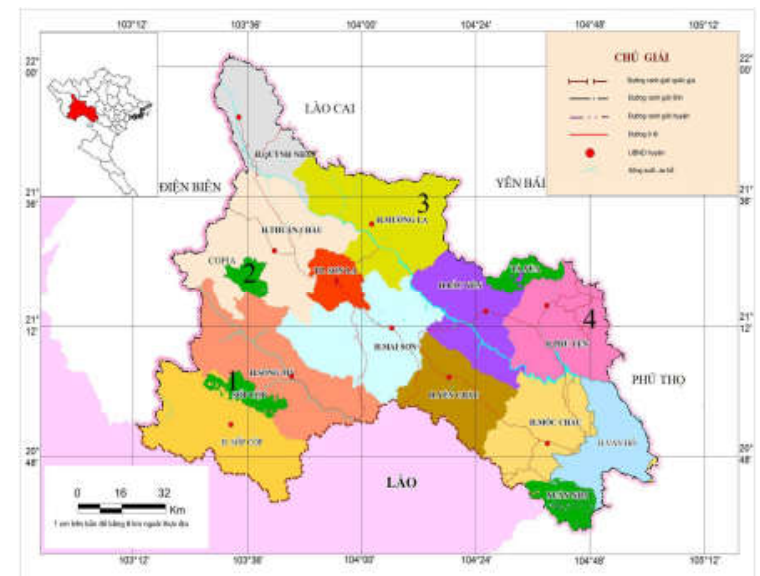

Hình 1: Vị trí các địa điểm thu mẫu tại tỉnh Sơn La:

1) KBTTN Sốp Cộp, 2) KBTTN Copia,

3) xã Ngọc Chiến và 4) xã Mường Do

Các chỉ số đo theo Bain et al., 2009 [6], với độ chính xác đến $0,1 \mathrm{~mm}$ bao gồm: SVL: Dài đầu và thân (từ mút mõm đến lỗ huyệt), HL: Dài đầu (từ mút mõm đến góc sau xương hàm dưới), HW: Rộng đầu (chiều rộng lớn nhất của đầu), $\mathrm{MN}$ : Khoảng cách góc sau hàm dưới mũi, MFE: Khoảng cách từ góc sau hàm dưới tới góc trước của mắt, $\mathrm{MBE}$ : Khoảng cách từ góc sau hàm dưới tới góc sau của mắt, SL: Dài mõm (từ mút mõm đển góc trước ở mắt), $\mathrm{IN}$ : Khoảng cách gian mũi, SNL: Khoảng cách từ mút mõm đến lỗ mũi, NEL: Khoảng cách từ góc trước ổ mắt đến lỗ mũi, ED: Đường kính ổ mắt theo chiều ngang, UEW: Chiều rộng mi mắt trên, IOD: Khoảng cách gian ổ mắt, $\mathrm{DAE}$ : Khoảng cách góc trước hai mắt, DPE: Khoảng cách góc sau hai mắt, $\mathrm{TD}$ : Đường kính màng nhĩ, TED: Khoảng cách giữa rìa trước màng nhĩ và góc sau ổ mắt, FLL: Dài cánh tay (từ nách đến khuỷu tay), HAL: Dài bàn tay (từ khửu tay đến mút ngón tay III), TFL: Dài ngón III, FL: Dài đùi (từ lỗ huyệt đê̂n đầu gối), TL: Dài ống chân (từ đầu gối đến gót chân), TBW: Rộng ống chân, FoL: Dài bàn chân (từ gót chân đến mút ngón chân IV).

Định loại theo các tài liệu của Bourret (1942) [7], Taylor (1962) [8], Bain et al. (2009) [6], Hecht et al. (2013) [9], Luu et al. (2014) [10] và Poyarkov et al. (2015) [11].

\section{Kết quả và thảo luận}

\subsection{Da dạng các loài ếch cây sần ở tỉnh Sơn La}

Dựa vào kết quả phân tích mẫu vật, chúng tôi ghi nhận 5 loài ếch cây sần thuộc giống Theloderma ở tỉnh Sơn La, trong đó có 4 loài ghi nhận mới cho tỉnh Sơn La bao gồm: $T$. albopunctatum, $T$. bicolor, $T$. gordoni và $T$. lateriticum (Bảng 1). Với kết quả nghiên cứu này chúng tôi đã nâng tổng số loài lưỡng cư hiện biết ở tỉnh Sơn La lên 45 loài.

Bảng 1. Danh sách các loài ếch cây sần ghi nhận ở tỉnh Sơn La

\begin{tabular}{lll}
\hline TT & Tên khoa học & $\begin{array}{l}\text { Nơi ghi } \\
\text { nhận }\end{array}$ \\
\hline & $\begin{array}{l}\text { Theloderma albopunctatum } \\
\text { (Liu and Hu, 1962) }\end{array}$ & $1,2,4,4$ \\
& $\begin{array}{l}\text { Theloderma bicolor (Bourret, } \\
\text { 1937) }\end{array}$ & 1,4 \\
& $\begin{array}{l}\text { Theloderma corticale } \\
\text { (Boulenger, 1903) } \\
\text { Theloderma gordoni Taylor, } \\
\text { 1962 }\end{array}$ & 1,3 \\
& 1,2 \\
& Nheloderma lateriticum Bain, \\
& 2 \\
\hline
\end{tabular}

Ghi chú: 1: KBTTN Copia; 2: KBTTN Sốp Cộp; 3: xã Mường Do và 4: xã Ngọc Chiến. 
Khu vực nghi nhận nhiều loài ếch cây sần nhất ở tỉnh Sơn La là KBTTN Copia (4 loài), tiếp theo là KBTTN Sốp Cộp (3 loài), ở hai xã Mường Do và Ngọc Chiến ghi nhận 2 loài.

\subsection{Các loài ếch cây sần ghi nhận bổ sung cho} khu hệ lữong cu ở tỉnh Sơn La

Theloderma albopunctatum (Liu and $\mathrm{Hu}$, 1962)/ Ếch cây sần an-bo-pan-ta (Hình 2)

Mẫu vật nghiên cứu $(\mathrm{n}=7)$ : TBUPAE 260 , 261 (q) thu vào tháng 4/2013; TBUPAE 627 $\left({ }^{1}\right)$ và TBUPAE $655(q)$ thu vào tháng 4/2014; TBUPAE $690($ ( $)$ và TBUPAE $727\left({ }^{\top}\right)$ thu vào tháng $6 / 2014$ ở KBTTN Copia $\left(21^{\circ} 21.118^{\prime} \mathrm{N}\right.$, 10335.337’E, $1445 \mathrm{~m}$ ). TBUPAE 327 (đực) thu vào tháng 6/2013 ở KBTTN Sốp Cộp $\left(21^{\circ} 00.340^{\prime} \mathrm{N}, 103^{\circ} 25.779^{\prime} \mathrm{E}, 1330 \mathrm{~m}\right)$. Hai mẫu bắt gặp ở xã Ngọc Chiến, huyện Mường La và 2 mẫu khác bắt gặp ở xã Mường Do, huyện Phù Yên.

Kích thước (mm): SVL: 30,5-32 (す), 30,3-32 (P); HL: 11,1-12,2 (ठ) $)$ 11,6-12,2 (†); HW: 11,0-11,3 (ð), 11,0-11,4 (+); MN: 10,7-11,5 (ठ), 10,5-11,9 (ㅇ) ; MFE: 7,9-8,1 (ठ) , 7,8-8,5 ()); MBE: 4,2-4,3 (ठ) , 4,1-5,3 ()); SL: 5,3-5,9 (ठ), 5-5,6 (ㅇ); ED: 3,9-4,1 (ठ) , 4,0-4,1 (ㅇ); UEW: 2,4-2,9 (ठ) , 2,3-3,0 (ㅇ); IN: 2,3 (ð), 2,2-2,4 ()); IOD: 3,7-3,7 (ठ)), 3,5-4,3 (ㅇ); DAE: 5,7-5,9 (ð), 5,5-6,6 (ㅇ); DPE: 10,0-10,2

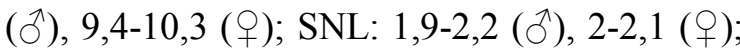
NEL: 3,4-3,5 (ठ), 3,3-3,5 (ㅇ); TD: 2,7-2,9 (ठ)), 2,6-2,9 (ㅇ); TED: 0,6-0,9 (ठ), 0,8-0,9 (ㅇ);

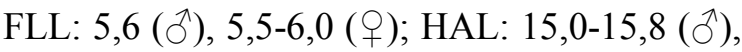
15,4-16,5 (); TFL: 5,1-5,2 (ठ) ), 5,0-5,5 (ㅇ); FL: 15,2-15,6 (す), 15,0-16,1 (ㅇ); TL: 15,8-17,2 (す), 16,0-16,6 (ㅇ); TBW: 3,1-3,5 (す) , 2,8-3,8 (ㅇ); FoL: 22,0 (ठ), 20,5-22,0 (ㅇ).

Kích cỡ trung bình, đầu dài hơn rộng; mút mõm tù; lỗ mũi hình ô van, hơi nhô ra ở mặt bên, nằm gần mắt hơn so với mút mõm; vùng má phẳng; khoảng cách gian ổ mắt lớn hơn chiều rộng mí mắt trên và khoảng cách gian mũi; đường kính mắt ngắn hơn dài mút mõm $(\mathrm{ED} / \mathrm{SL}$ 0,66-0,77 (đ) và 0,71-8,2 (ㅇ)), màng nhĩ rõ ràng, tròn, lớn hơn khoảng cách từ màng nhĩ tới mắt, nhỏ hơn đường kính mắt $(\mathrm{TD} / \mathrm{ED}$ $0,69-0,71\left({ }^{3}\right)$ và $\left.0,65-0,71(+)\right)$. Lưỡi có khía ở phía sau, không có răng lá mía. Gờ da phía trên màng nhĩ không rõ ràng.

Chi trước mảnh, tương quan chiều dài giữa các ngón: $\mathrm{I}<\mathrm{II}<\mathrm{IV}<\mathrm{III}$; mút ngón tay có đĩa bám phát triển; giữa các ngón tay không có màng bơi; chai dưới khớp ngón tay rõ, hình ô van, công thức: 1:1:2:2; củ bàn trong rõ; không có chai sinh dục ở con đực.

Chi sau: tương quan chiều dài giữa các ngón chân $\mathrm{I}<\mathrm{II}<\mathrm{V} \leq \mathrm{III}<\mathrm{IV}$; mút ngón chân có đĩa bám phát triển nhưng nhỏ hơn ngón tay; màng bơi giữa các ngón chân có khoảng $3 / 4$, công thức màng bơi: I0-1II0-1 1/2III0-1 1/2IV1$0 \mathrm{~V}$; chai dưới khớp ngón rõ, công thức: $1: 1: 2: 3: 2$; củ bàn trong rõ.

Da: mặt lưng và hai bên có các nốt sần nhỏ; cằm nhẵn; bụng và mặt dưới các chi có các nốt sần nhỏ.

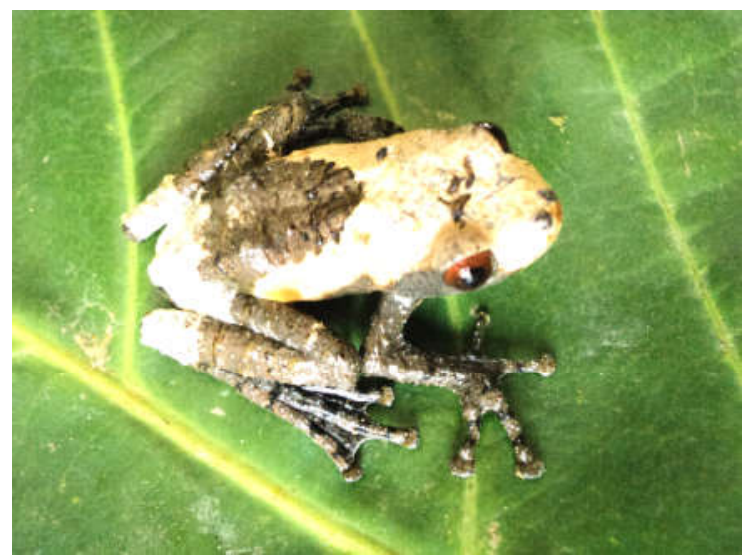

Hình 2. Ếch cây sần an-bo-pan-ta T. albopunctatum

Màu sắc: Mẫu vật khi còn sống có mặt lưng màu kem; trên đầu có một vệt đen hình tam giác; vùng vai có vệt xám kéo xiên về phía hông, gần hông màu kem; giữa lưng có một vệt đen lớn; phần sau lưng kem; dưới cằm xám; bụng và bên dưới các chi nâu, với các sọc xám nhỏ (định loại theo Taylor, 1962 [7]; Luu et al., 2014 [10]; Poyarkov et al., 2015 [11]).

Một số đặc điểm sinh thái học: mẫu vật của loài $T$. albopunctatum bắt gặp vào ban ngày ở 
các hốc đá, cây to có nước đọng; ban đêm gặp vào khoảng 20:00-22:00 trên lá cây ven suối trong rừng thường xanh gồm cây gỗ vừa và nhỏ, xen cây bụi.

Phân bố: Trên thế giới, loài ếch này được ghi nhận ở Trung Quốc và Lào [11]. Ở Việt Nam, loài ếch này được ghi nhận ở Lai Châu, Hà Giang vào đến Lâm Đồng và Đồng Nai [3].

Theloderma bicolor (Bourret, 1937)/ Ếch cây sần hai màu (Hình 3)

Mẫu vật nghiên cưu $(\mathrm{n}=7)$ : TBUPAE 328 (q) thu vào tháng 6/2013 ở KBTTN Copia $\left(21^{\circ} 20.274^{\prime} \mathrm{N}, \quad 103^{\circ} 34.708^{\prime} \mathrm{E}, \quad 1465 \mathrm{~m}\right)$; SL2015.55 (O) thu vào tháng 4/2015 ở bản Nậm Nghẹp, xã Ngọc Chiến, huyện Mường La (213․ $\left.363^{\prime} \mathrm{N}, 104^{\circ} 15.810^{\prime} \mathrm{E}, 1770 \mathrm{~m}\right)$.

Kích thước $(\mathrm{mm}),\left({ }^{\Uparrow}\right)$ : SVL: 34,0-48,1; HL: 13,0-19,3; HW: 12,7-18,5; MN: 11,9-17,3; MFE: 8,8-12,5; MBE: 4,7-7,9; SL: 5,5-8,6; ED: 5,3-6,3; UEW: 3,2-4,6; IN: 2,3 3,1-4,0; IOD: 3,6-5,7; DAE: 6,2-9,3; DPE: 11,0-16,2; SNL: 1,9-3,0; NEL: 4,0-5,9; TD: 2,6-4,3; TED: 1,31,7; FLL: 7,5-10,9; HAL: 16,7-26,5; TFL: 7,09,6; FL: 17,5-24,6; TL: 18,1-25,9; TBW: 3,83,9; FoL: 22,6-34,4; IMT: 1,5-1,6.

Kích cỡ trung bình, đầu dài hơn rộng; mút mõm tù; lỗ mũi hình ô van, nhô ra phía trước, nằm gần mắt hơn so với mút mõm; vùng má lõm; khoảng cách gian ổ mắt lớn hơn rộng mí mắt trên và khoảng cách gian mũi; đường kính mắt ngắn hơn dài mõm ( $\mathrm{ED} / \mathrm{SL} \quad 0,73-0,96)$; màng nhĩ rõ ràng, tròn, lớn hơn khoảng cách từ màng nhĩ tới mắt, nhỏ hơn đường kính mắt (TD/ED 0,49-0,68). Lưỡi ngắn, rộng, có khía ở phía sau, răng lá mía nhỏ. Gờ da phía trên màng nhĩ không rõ ràng.

Chi trước mảnh, tương quan chiều dài giữa các ngón: $\mathrm{I}<\mathrm{II}<\mathrm{IV}<\mathrm{III}$; mút ngón tay có đĩa bám; giữa các ngón tay không có màng bơi; chai dưới khớp ngón tay rõ, tròn, công thức: 1:1:2:2; củ bàn trong rõ; chai sinh dục không phát triển.

Chi sau: tương quan chiều dài giữa các ngón chân $\mathrm{I}<\mathrm{II}<\mathrm{III} \leq \mathrm{V}<\mathrm{IV}$; mút ngón chân có đĩa bám phát triển nhưng nhỏ hơn ngón tay; màng bơi giữa các ngón chân gần hoàn toàn, công thức màng bơi: I0-1II0-1III0-1 1/2IV1 1/2$1 / 2 \mathrm{~V}$; chai dưới khớp ngón rõ, công thức: $1: 1: 2: 3: 2$; củ bàn trong rõ.

Da: mặt lưng có các nốt sần lớn, nhọn; hai bên sườn có các nốt sần nhỏ; cằm có một số nốt sần nhỏ; bụng và mặt dưới các chi ráp.

Màu sắc: Mẫu vật khi còn sống có mặt lưng xanh rêu, có các vệt xanh sẫm màu lớn; bên hông có các đốm đen tròn lớn; mặt trên chân có các vệt ngang sẫm màu; bụng có các đốm đen lớn xen kẽ các sọc đứt đoạn trắng (định loại theo Bouret, 1942 [7]).

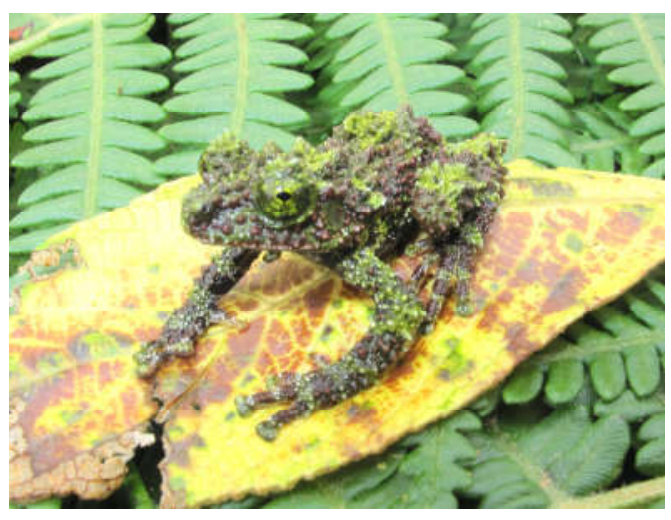

Hình 3. Ếch cây sần hai màu Theloderma bicolor

Một số đặc điểm sinh thái học: mẫu vật của loài $T$. bicolor được thu vào khoảng 19:3021:30 trên lá cây ở ven suối trong rừng thường xanh gồm cây gỗ vừa và nhỏ xen cây bụi.

Phân bố: Đây là loài ếch rất hiếm gặp, mới chỉ ghi nhận ở hai tỉnh Lào Cai và Quảng Trị của Việt Nam [3].

Theloderma gordoni Taylor, 1962/ Ếch cây sần gô-đôn (Hình 4)

Mẫu vật nghiên cúu $(\mathrm{n}=7)$ : TBUPAE 217 $(\widehat{)})$, thu vào tháng $11 / 2012$ ở KBTTN Sốp Cộp $\left(20^{\circ} 56.916^{\prime} \mathrm{N}, \quad 103^{\circ} 40.559^{\prime} \mathrm{E}, 1030 \mathrm{~m}\right)$; TBUPAE 531 ( $\left.0^{\Uparrow}\right)$ và TBU PAE 529, 532 (q) thu vào tháng 9/2013; TBUPAE 624 (ठ̊) thu vào tháng 4/2014 ở KBTTN Copia $\left(21^{\circ} 19.953^{\circ} \mathrm{N}, \quad 103^{\circ} 35.283^{\prime} \mathrm{E}, \quad 1470 \mathrm{~m}\right)$. SL2015.243 (ठ) thu vào tháng $5 / 2015$ ở KBTTN Sốp Cộp $\left(21^{\circ} 00.101^{\prime} \mathrm{N}, 1^{103^{\circ}} 25.770^{\prime} \mathrm{E}\right.$, $1515 \mathrm{~m})$. 
Kích thước: SVL: 36,5-44,7 (ठ)), 48,0-50,2 (ㅇ); HL: 14,9-17,8 (ठ), 19,0-19,8 (ㅇ); HW: 15,018,3 (ठ) , 19,7-19,9 (ㅇ); MN: 14,0-16,6 (ठ), 17,8 (ㅇ); MFE: 10,0-12,5 (ठ), 13,0-13,3 (ㅇ); MBE: 5,8-7,0 (ð), 7,9-8,2 (ㅇ); SL: 6,6-7,5 (ठ), 7,9-9,0 (ㅇ); ED: 5,2-5,5 (ð), 5,2-5,6 (ㅇ); UEW: 4,0-4,5 (ठ) , 4,1-4,6 (); IN: 3,1-3,9 (ठ), 3,7-4,3 (ㅇ); IOD: 4,6-6,4 (ठ), 6,8-7,2 ()); DAE: 7,0-9,2 (ठ), 9,8-10,4 ()); DPE: 12,515,1 (ð) $, 15,3-16,4$ (ㅇ); SNL: 2,5-3,0 (ð), 3,33,5 ()); NEL: 4,7-5,5 (ふ), 6,2-6,7 (); TD:

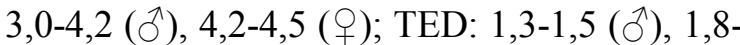
1,9 (市); FLL: 7,2-9,0 (ठ), 9,0-9,5 (q); HAL:

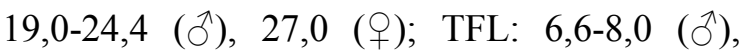
10,0-10,2 (ㅇ); FL: 17,5-21,5 (ठ), 22,6-23,5 (); TL: 18,2-22,4 (ठ), 24,2-24,9 (ㅇ); TBW: 3,4-4,6 (す), 4,7 ()); FoL: 24,8-30,2 (す), 32,333,0 (ㅇ); IMT: 1,9-2,6 (す) ), 2,7 (ㅇ).

Kích cỡ trung bình, đầu rộng hơn dài; lỗ mũi hình ô van, nhô ra phía trước, nằm gần mắt hơn so với mút mõm; vùng má lõm; khoảng cách gian ổ mắt lớn hơn chiều rộng mí mắt trên và khoảng cách gian mũi; đường kính mắt ngắn hơn dài mút mõm $(\mathrm{ED} / \mathrm{SL} \quad 0,72-0,79$ (ठ) và 0,58-71 (q)); màng nhĩ rõ ràng, tròn, lớn hơn khoảng cách từ màng nhĩ tới mắt, nhỏ hơn đường kính mắt $\left(\mathrm{TD} / \mathrm{ED} 0,57-0,77\left(\mathrm{O}^{7}\right)\right.$ và 0,80 $0,81($ ()). Lưỡi có khía ở phía sau, có răng lá mía cạnh lỗ mũi trong. Gờ da phía trên màng nhĩ không rõ ràng.

Chi trước: tương quan chiều dài giữa các ngón: $\mathrm{I}<\mathrm{II}<\mathrm{IV}<\mathrm{III}$; mút ngón tay có đĩa bám phát triển; giữa các ngón tay không có màng bơi; chai dưới khớp ngón tay rõ, gần tròn, công thức: 1:1:2:2; củ bàn trong rõ; chai sinh dục ở con đực phát triển.

Chi sau: tương quan chiều dài giữa các ngón chân $\mathrm{I}<\mathrm{II}<\mathrm{III}<\mathrm{V}<\mathrm{IV}$; mút ngón chân có đĩa bám phát triển nhưng nhỏ hơn ngón tay; màng bơi giữa các ngón chân có khoảng $1 / 2$, công thức màng bơi: $I 1-1 \frac{1}{2}\left[I^{1} / 2-13 / 4 I^{3} I^{3} / 4-2 I V 2-\right.$ $1 \mathrm{~V}$; chai dưới khớp ngón rõ, công thức: $1: 1: 2: 3: 2$; củ bàn trong rõ.
Da: mặt lưng có các nốt sần lớn, nhọn; mặt bên có các nốt sần nhỏ, đôi khi không rõ; cằm có nhiều nốt sần nhỏ; bụng và mặt dưới các chi có các nốt sần nhỏ.

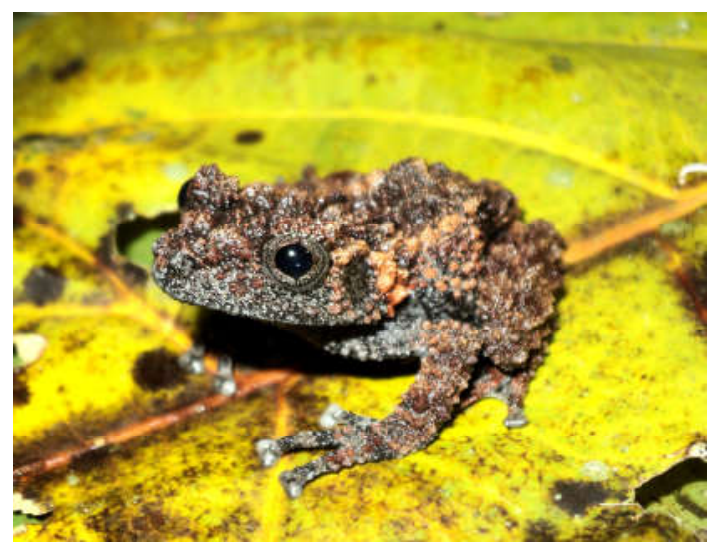

Hình 4. Ếch cây sần gô-đôn Theloderma gordoni.

Màu sắc: Mẫu vật khi còn sống có mặt trên lưng màu nâu đen, mép lưng sườn và phía sau đùi vàng nhạt; bụng và bên dưới các chi nâu, có các đốm đen nhỏ (định loại theo Taylor, 1962 [8]).

Một số đặc điểm sinh thái học: mẫu vật của loài $T$. gordoni được thu ở các hốc cây to có nước đọng; ban đêm gặp khoảng 20:00-22:00, trên lá cây ở ven suối trong rừng thường xanh gồm cây gỗ vừa và nhỏ, xen cây bụi.

Phân bố: Trên thế giới loài ếch này được ghi nhận ở Trung Quốc, Lào và Thái Lan [3]. Ở Việt Nam, loài ếch này được ghi nhận ở Lai Châu, Lào Cai, Vĩnh Phúc, Cao Bằng, Lạng Sơn, Gia Lai và Kon Tum [3].

Theloderma lateriticum Bain, Nguyen \& Doan, 2009/ Ếch cây sần đỏ (Hình 5)

Mẫu vật nghiên cứu $(\mathrm{n}=2)$ : TBUPAE $226(\widehat{\jmath})$, TBUPAE 227 (q) thu vào tháng 4/2013 ơ KBTTN Sốp Cộp $\left(21^{\circ} 00.876^{\prime} \mathrm{N}, 103^{\circ} 34.818^{\prime}\right.$ E, $1410 \mathrm{~m}$ ).

Kích thước: SVL: 24,8 (す), 22,9 ()); HL: 9,2

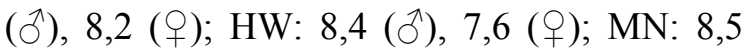


(ठ), 6,9 (只); MFE: 6,2 (ð), 5,7 (q); MBE: 3,3

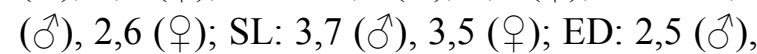

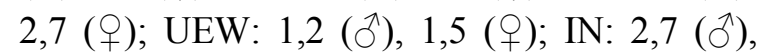
2,3 (官); IOD: $3,1($ đ), $2,8($ ( $) ;$ DAE: $4,5($ đ),

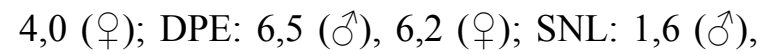

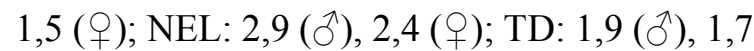
(+); TED: 0,6 (す), 0,5 ()); FLL: 5,1 (ð), 3,5 (ㅇ); HAL: 11,4 (ð), 10,8 (ㅇ); TFL: 3,7 (ठ),

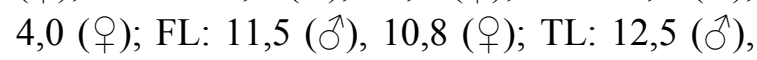
11,9 (ㅇ); TBW: 1,8 (đ) $, 1,8$ (); FoL: 17,1 (đ) $, 15,5$ (ㅇ) .

Kích cỡ; đầu dài hơn rộng; mút mõm tù khi nhìn từ trên xuống; lỗ mũi hình ô van, hơi nhô ra phía trước, nằm gần mắt hơn so với mút mõm; vùng má hơi lõm; khoảng cách gian ổ mắt lớn hơn chiều rộng mí mắt trên và khoảng cách gian mũi; đường kính mắt ngắn hơn dài mút mõm (ED/SL 0,68-0,82 ở con đực và 0,77 ở con cái), con ngươi ngang, hình ô van; màng nhĩ rõ ràng, tròn, lớn hơn khoảng cách từ màng nhĩ tới mắt, nhỏ hơn đường kính mắt $(\mathrm{TD} / \mathrm{ED}$ 0,61-0,72 ở con đực và 0,63 ở con cái). Lưỡi có khía ở phía sau; không có răng lá mía. Gờ da phía trên màng nhĩ không rõ ràng.

Chi trước: tương quan chiều dài giữa các ngón: $\mathrm{I}<\mathrm{II}<\mathrm{IV}<\mathrm{III}$; mút ngón tay có đĩa bám phát triển; giữa các ngón tay không có màng bơi; chai dưới khớp ngón tay rõ, tròn, công thức: 1:1:2:2; củ bàn trong rõ; chai sinh dục ở con đực phát triển.

Chi sau: tương quan chiều dài giữa các ngón chân $\mathrm{I}<\mathrm{II}<\mathrm{III}<\mathrm{V}<\mathrm{IV}$; mút ngón chân có đĩa bám phát triển nhưng nhỏ hơn ngón tay; màng bơi giữa các ngón chân có khoảng $1 / 4$, công thức màng bơi: $\mathrm{I} 1^{1 / 2}-2 \mathrm{II} 1^{1 / 2} / 2-2 \mathrm{III} 1-$ $2 \frac{1}{2} \mathrm{IV} 2 \frac{1}{2}-2 \mathrm{~V}$; chai dưới khớp ngón rõ, công thức: $1: 1: 2: 3: 2$; củ bàn trong rõ.

Da: mặt lưng có các hạt nhỏ; mí mắt, đùi và sườn trên có các nốt sần nhỏ; bụng ráp.
Màu sắc: Mẫu vật còn sống có màu đỏ nâu trên lưng, có một vài đốm đen lớn ở giữa hai mắt và lưng; cánh tay và đùi đỏ nâu, với các vệt ngang màu đen; bụng nâu xám, với các đốm sáng nhỏ (định loại theo Bain et al., 2009 [6]; Hecht et al., 2013 [9]).

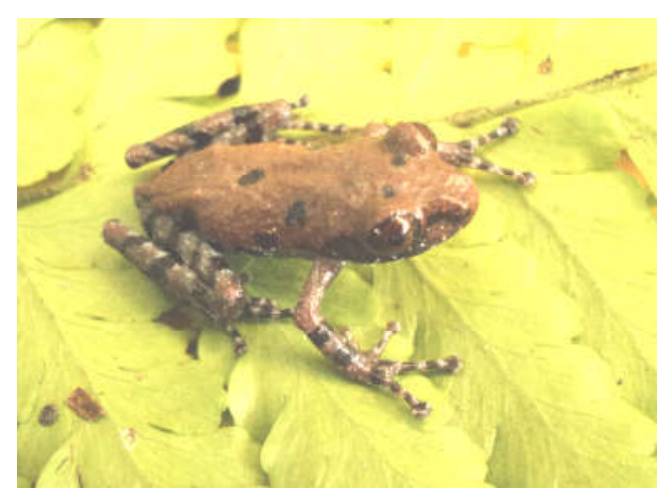

Hình 5. Ếch cây sần đỏ Theloderma lateriticum

Một số đặc điểm sinh thái học: mẫu vật của loài $T$. lateriticum được thu trong ống tre có nước vào lúc 16:00 trong rừng thường xanh hỗn giao tre gỗ.

Phân bố: Loài ếch này mới được mô tả ở Việt Nam năm 2009 với mẫu chuẩn thu ở Lào Cai; gần đây loài này đã được ghi nhận ở Hòa Bình và Bắc Giang [6], [9].

\section{Kết luận}

Chúng tôi đã ghi nhận năm loài ếch cây sần thuộc giống Theloderma ở tỉnh Sơn La. Trong số này có bốn loài bổ sung cho khu hệ lưỡng cư của tỉnh Sơn La là T. albopunctatum, T. bicolor, $T$. gordoni và $T$. lateriticum. Bên cạnh đó, chúng tôi cũng mô tả đặc điểm hình thái và cung cấp một số đặc điểm sinh thái học của bốn loài ghi nhận mới. Với kết quả nghiên cứu này, đã nâng tổng số loài lưỡng cư hiện biết ở tỉnh Sơn La lên 45 loài.

\section{Lời cảm ơn}

Các tác giả xin cảm ơn các sinh viên Từ Văn Hoàng, Khăm Đi Pheng Kia Chư, Nguyễn 
Văn Tân đã cùng tham gia khảo sát thực địa. Nghiên cứu này được tài trợ bởi quỹ phát triển khoa học công nghệ trường Đại học Tây Bắc, trong đề tài mã số: TB2015-12 và nguồn ngân sách Nhà nước của Bộ Giáo dục trong đề tài cấp bộ Giáo dục, mã số B2016-TTB-01.

\section{Tài liệu tham khảo}

[1] Cục Kiểm lâm, http://www.kiemlam.org.vn/, tham khảo số liệu diễn biến rừng tháng tính đến tháng 12 năm 2016. Tra cứu ngày 19/10/2017.

[2] Lê Nguyên Ngật, Nguyễn Văn Sáng, Kết quả khảo sát lưỡng cư, bò sát ở Khu Bảo tồn thiên nhiên Copia, tỉnh Sơn La, Kỷ yếu Hội nghị khoa học toàn quốc về Sinh thái và Tài nguyên sinh vật lần thứ 3 (2009), tr:467-471.

[3] Nguyen, S.V., Ho, C. T., Nguyen, T. Q., Herpetofauna of Vietnam. Edition Chimaira, Frankfurt am Main, 2009.

[4] Nguyễn Văn Sáng, Nguyễn Xuân Đặng và Nguyễn Quảng Trường, Đa dạng về thành phần loài Bò sát và Éch nhái ở Khu Bảo tồn thiên nhiên Xuân Nha, tỉnh Sơn La, Tạp chí Sinh học, 32(4) (2010), tr:54-61.

[5] Phạm Văn Anh, Từ Văn Hoàng, Khăm Đi Pheng Kia Chư, Nguyễn Quảng Trường, Nguyễn Lân Hùng Sơn, Nguyễn Kim Tiến, Thành phần loài Lưỡng cư (Amphibia) và Bò sát (Reptilia) ở Thành phố Sơn La, tỉnh Sơn La, Kỷ yếu Hội nghị khoa học toàn quốc về Sinh thái và Tài nguyên sinh vật lần thứ 6 (2015) tr: 461-467.

[6] Bain, R. H., Nguyen, Q. T. and Doan, V. K., A new species of the genus Theloderma Tschudi, 1838 (Anura: Rhacophoridae) from northwestern Vietnam, Zootaxa, 2191 (2009): 58-68.

[7] Bourret, R., Les Batraciens de l'Indochine [Hanoi], Institut Océanographique de l'Indochine, 1942.

[8] Taylor, E. H., The Amphibian fauna of Thailand, The University of Kansas Science Bulletin, Vol. XLIII, No.8, 1962.

[9] Hecht, V. L., Pham, C. T., Nguyen, T. T., Nguyen, T. Q., Bonkowski, M. \& Ziegler T., First report on the herpetofauna of Tay Yen Tu Nature Reserve, northeastern Vietnam, Biodiversity Journal, 4(4) (2013): 507-552.

[10] Luu, Q. V., Le, X. C., Do, Q. H., Hoang, T. T., Nguyen, Q. T., Bonkowski, M. \& Ziegler, T., New records of amphibians from Thuong Tien Nature Reserve, Hoa Binh Province, Vietnam, Herpetology Notes, 7 (2014): 51-58.

[11] Poyarkov, N. A., Jr., Orlov, N. L., Moiseeva, A. V., Pawangkhanant, P., Ruangsuwan, T., Vassilieva, A. B., Galoyan, E. A., Nguyen, T. T., Gogoleva, S. I., Sorting out Moss Frogs: mtDNA data on taxonomic diversity and phylogenetic relationships of the Indochinese species of the genus Theloderma (Anura, Rhacophoridae), Russian Journal of Herpetology, 22 (2015): 241280.

\title{
Diversity of the genus Theloderma (Amphibia: Anura: Rhacophoridae) from Son La Province
}

\author{
Pham Van Anh ${ }^{1}$, Nguyen Quang Truong ${ }^{2,3}$ \\ ${ }^{1}$ Tay Bac University, Son La City, Son La Province, Vietnam \\ ${ }^{2}$ Institute of Ecology and Biological Resources, \\ ${ }^{3}$ Graduate University of Science and Technology, Vietnam Academy of Science and Technology, \\ 18 Hoang Quoc Viet, Hanoi, Vietnam
}

\begin{abstract}
We recorded five species of the genus Theloderma on the basis of new amphibian collection from Son La province from 2012 to 2016. Among them, four species, Theloderma albopunctatum, T. bicolor, T. gordoni and T. lateriticum, are recorded for the first time from this province. Our findings brought the total number of amphibian species recorded from Son La province up to 45 . We also provide additional information about morphology and natural history of the afore mentioned species.
\end{abstract}

Keywords: Copia, Muong Do, Muong La, New records, Sop Cop, Theloderma 